Erik Knain er professor i realfagdidaktikk og forskningsleder ved SLL. Han har arbeidet med ulike prosjekter med språkbruk i naturfag som tema, fra ideologier i lærebøker (doktoravhandling) til tekstutvikling i wiki i tverrfaglige prosjekter. Han er prosjektleder for "Elever som forskere i naturfag" som inngår i Norges forskningsråds program PraksisFoU. Målet med prosjektet er å utvikle utforskende arbeidsmåter i skolen. Han har hovedfag i astronomi.

ERIK KNAIN

Universitetet for miljø- og biovitenskap

Institutt for matematiske realfag og teknologi (IMT)

Seksjon for læring og lærerutdanning (SLL)

erik.knain@umb.no

\title{
Hvordan åpne for vitenskapshistorie i naturfagundervisning
}

\begin{abstract}
How to represent the nature of science in an authentic way so that the argumentative aspect of science inquiry is not lost is investigated in terms of representations of the history of science. By comparing representations of the development of the Big Bang theory, successive shifts from Big Bang as an established fact to the processes of establishing this fact points to dilemmas and choices involved in teaching the nature of science. Texts from school textbooks, from a historian of science (Helge Kragh) and from a science sociologist (Bruno Latour) are discussed in order to point to key steps from product to process. Three levels of depth in tracing the historical development of a scientific fact are inferred.
\end{abstract}

\section{IN NLEDNING}

At elever i skolen skal lære om naturvitenskap som prosess, ikke bare som sluttprodukt, er et vedvarende tema i naturfagdidaktikk. Også Forskerspiren i LK06 åpner med denne distinksjonen mellom naturvitenskap som prosess og produkt (Utdanningsdirektoratet, 2006). Omtrent like lenge er det reist kritikk mot at naturvitenskap som prosess blir misrepresentert i skolen (Hodson, 1996). I norsk sammenheng fant Knain (2001) at lærebøker i naturfag formidler et individsentret syn på naturvitenskap som prosess. Matthews (1994) skiller mellom et minimumssyn på vitenskapshistoriens rolle, og et maksimumssyn. I det første tilfellet knyttes vitenskapshistoriske poenger til fagstoff (for eksempel historiske poenger om Newton når F=ma er tema), mens i det andre tilfellet blir undervisning strukturert slik at prosessiden kommer i førersetet. I denne artikkelen skal vi gå nærmere inn på dette spørsmålet: Hvordan kan undervisningen utvides fra en minimumsvariant i retning av en maksimumsvariant? På hvilken måte endres framstillingen når prosessen åpnes i stadig større detalj? I dette ligger et dilemma ved at jo mer vekt det legges på prosess slik at denne blir mer autentisk og i tråd med hvordan forskning faktisk foregår, jo mer utydelig blir veien fram til et faktum. Samtidig, hvis en i ettertid peker på de tydeligste trådene fram til et faktum, kan vitenskapshistorien framstå som sterkt forenklet inntil det misvisende, hvor den argumenterende siden av prosessen blir særlig skadelidende (Driver, Newton, \& Osborne, 2000). 
I denne læreboka har forfatterne valgt å fokusere på den etablerte kunnskapen. Da boka ble utgitt var denne framstillingen faglig riktig. I det neste eksemplet skal vi se at universets alder nå har blitt adskillig mer presist bestemt. Hva kan vi lære om naturvitenskap som virksomhet hvis vi nærmer oss prosessene som gjorde at astronomene ble enige om at det er faktisk slik det forholder seg? For å få svar på det skal vi undersøke hva som menes med at astronomene "ser" at universet ekspanderer når de studerer galaksene. "Ser" fungerer som en metafor i denne framstillingen, og legger samtidig til rette for at et individsentrert syn blir forsterket og elevene tar "ser" bokstavelig: Astronomen kan rette teleskopet mot himmelen, og se at galaksene flyr bort fra hverandre. Hvis det etableres et inntrykk av at kunnskap er noe som uten videre direkte "ses" i laboratoriet, har vi kommet til utfordringer som følger med å la vitenskapshistorien vise tydelig veien til faktum. Et annet poeng er at Big Bang framstår som en logisk konsekvens av universets ekspansjon. Big Bang blir på en måte en konsekvens av hvordan "Naturen" er. Dette poenget følges opp gjennom Bruno Latour senere i denne artikkelen.

Et annet signal om at det i denne teksten handler om kunnskapsproduktet, er den underforståtte konsensus som ligger $i$ at astronomene omtales som enhetlig gruppe. Astronomene mener..., astronomene ser... Når vitenskapshistorien pakkes sammen så vidt tett, framstår universets ekspansjon som en logisk konsekvens av Big Bang, som tilgjengelig for direkte observasjon.

I det andre teksteksemplet er vinklingen noe annerledes, her er vitenskapshistorien mer framme:

\title{
Ideen om det store smellet
}

\author{
Hwor gigantisk universet virkelig er, forstod man ikke for pa 1920-tallet. 4a \\ astrooomer fikk teleshoper som var gode nok til â undersake andre galakser enn \\ Mellieveien. De oppdaget ogsi at alle galaksene i universet beveger seg vekk fra \\ hverandre. Det gav opphav til ideen om at det hele startet $i$ ett punkt og deretter \\ utvidet seg etter et storsmell, et -big bangs, I 1966 filk dene ideen statte av en \\ annen viktig oppalagelse.

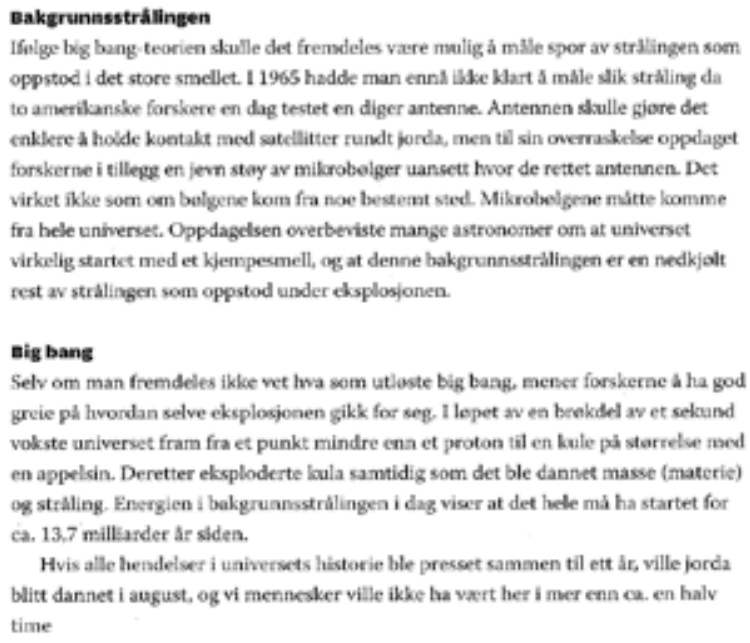

Figur 2. Framstilling av Big Bang kosmologien med vekt på naturvitenskap som prosess. Finstad, H. S., Kolderup, J., \& Jørgensen, E. C. (2006, 292). 
Denne framstillingen starter med det vitenskapshistoriske. Det som kommer fram her, er en utvikling fra 1920 til 1965. I denne teksten er også de sentrale observasjonene nevnt, og observasjon og slutning er ikke uløselig knyttet sammen. Astronomer får ideer fra observasjoner, som siden bekreftes av nye observasjoner. Astronomene er ikke en ensartet gruppe lenger; "mange astronomer" ble "overbevist". I dette er det antydninger som kan følges opp videre: Hvordan blir forskere overbevist? Hvorfor ble ikke astronomene overbevist før i 1965?

\section{Big BANG I VITENSKAPSHISTORIEN}

I fortsettelsen skal vi gå inn i større detalj i to ulike framstillinger av utviklingen av Big Bang kosmologien, i ulik detaljgrad. Den ene framstillingen er fra boken "Quantum Generations" av Helge Kragh (1999). Her blir kosmologiens utvikling viet et kapittel. Deretter skal vi gå nærmere inn på en episode i en bok som i sin helhet er viet samme tema, "Cosmology \& Controversy", også skrevet av Helge Kragh (1996). At disse tekstene er skrevet av samme forfatter men i ulike detaljgrad gjør at vi kan få øye på et "zoom" aspekt ved vitenskapshistorien. I begge tilfeller er det denne forfatterens perspektiv vi ser dette gjennom.

Går vi videre inn i vitenskapshistorien, vil vi se at Big Bang som faktum

1. Utviklet seg i flere etapper

2. Utviklingen gikk ikke i rett linje

3. Det fantes konkurrerende forklaringer på samme observasjoner.

Hvilke utviklingstrekk er det snakk om? I tabell 1 følger utviklingslinjen slik vi finner den dekket i ett kapittel i Quantum Generations (Kragh, 1999).

Med oppdagelsen av den kosmiske bakgrunnsstrålingen var Big Bang stødig som teori. Nye målinger av bakgrunnsstrålingen og fjerne galakser har gjort at de grunnleggende variablene, som universitets alder, ekspansjonsforløp og fordeling av ulike typer masse er kjent. Vi lever i dag i et univers som er 13.7 milliarder år gammelt, som ekspanderer stadig raskere pga en "mørk energi", som sammen med "mørk materie" utgjør $96 \%$ av alt som finns. Universet har ikke blitt et mindre mysterium!

"Steady State" teorien ble lansert i 1948 som en konkurrerende teori til Big Bang teorien. Den bygget på et postulat om at universet overalt var det samme, og ikke endret seg over tid. Nye atomer oppstod av ingenting og erstattet materie som ble tynnet ut som følge av ekspansjonen. Teorien ble forlatt av forskersamfunnet i 1960 på grunn av radioobservasjoner som viste at det var flere radiokilder i det tidlige universet enn i dag. Dette ble tolket som et brudd på et av de sentrale postulatene i teorien: at universet er likt over alt og til alle tider. Steady State nevnes også som alternativ til Big Bang i læreboken Trigger (s. 296) omtalt i nåtid. Tatt i betraktning at teorien også er forlatt av dens opphavsmenn burde den vært omtalt i fortid.

Fra den konsensus som gjør Big Bang kosmologien til et faktum, kan en peke på en utviklingstråd bakover (hvordan astronomene fant ut at naturen er slik), og hva som er forstyrrelser, eller det Kragh kaller "sosiologiske faktorer". For å forklare hvorfor en grunnleggende riktig teori ble mer eller mindre glemt i en tiårsperiode (fra 1955 til oppdagelsen av bakgrunnsstrålingen i 1965) trekker Kragh fram at teorien var skrevet langt på vei i kjernefysikkens språkdrakt, noe som kunne gjøre den fremmedartet for astronomer. På midten av 50-tallet kom nye konkurrerende forskningsfronter med utviklingen av transistoren og nye store astronomiske observatorier. På den tiden var det også en viss dalende interesse for generell relativitetsteori, som var en hjørnestein i kosmologien. Kragh nevner også personlige faktorer som opplagt har mye å si i et lite forskermiljø, som at Gamov hadde en tendens til å miste interessen for nye teorier etter at deres første friskhet var falmet. Det var også kjent at han slet med et alkoholproblem. 
Tabell 1. De viktigste milepcelene i utviklingen av Big Bang kosmologien $i$ henhold til kapitlet viet kosmologi i Quantum Generations (Kragh, 1999).

\begin{tabular}{|c|c|}
\hline 1917 & $\begin{array}{l}\text { Albert Einstein publiserer sin generelle relativitetsteori, som knytter gravitasjon til en } \\
\text { egenskap ved selve rommet (krumming). Denne egenskapen henger sammen med } \\
\text { massefordelingen i verdensrommet. Kort sagt: Sola påvirker rommet omkring seg, som } \\
\text { påvirker banen til planetene. Planetene går så rett fram som de kan, men på grunn av } \\
\text { rommets krumming blir de ellipsebaner. Einsteins ligninger åpnet for en matematisk } \\
\text { beskrivelse av universets struktur i form av krumming av rommet. }\end{array}$ \\
\hline 1922 & $\begin{array}{l}\text { Alexander Friedmann gir en matematisk beskrivelse av et univers som ekspanderer, } \\
\text { Georgies Lemaître kom til samme konklusjon i } 1927 .\end{array}$ \\
\hline 1930 & $\begin{array}{l}\text { Konsensus om at universet ekspanderer etablert etter Hubbles empiriske studier av } \\
\text { galakser. }\end{array}$ \\
\hline 1931 & $\begin{array}{l}\text { Lemîtres introduserer ideen om et "uratom" som via radioaktive prosesser blir til dagens } \\
\text { grunnstoffer. }\end{array}$ \\
\hline 1938 & $\begin{array}{l}\text { Kjernefysikk entrer kosmologien: Carl Friedrich Von Weizsäcker forsøker å forstå } \\
\text { universets utvikling gjennom kjernefysiske prosesser. Hypotese om at universet startet } \\
\text { med atomets tetthet og med temperatur } 200 \text { milliarder grader. }\end{array}$ \\
\hline 1942 & $\begin{array}{l}\text { Konklusjon i konferanserapport fra den } 8 \text {. Washington konferansen i teoretisk fysikk: } \\
\text { "the elements originated in a process of explosive character, which took place at "the } \\
\text { beginning of time" and resulted in the present expansion of the universe" (Kragh, 1999, } \\
\text { p. 351). }\end{array}$ \\
\hline 1946 & $\begin{array}{l}\text { Kjernefysikk og relativitetsteori kobles sammen: Kjernespalting i ekspanderende } \\
\text { univers. }\end{array}$ \\
\hline 1948 & $\begin{array}{l}\text { Det tidlige universet oppfattes av amerikanerne George Gamow og Herman Alpher som } \\
\text { å bestå av stråling. "Resten” av denne strålingen forutsies i dag å ha temperaturen } 5 \mathrm{~K} \\
\text { ( } 268 \text { kuldegrader). }\end{array}$ \\
\hline 1953 & Klassisk Big Bang kosmologi fullt utviklet. \\
\hline 1965 & $\begin{array}{l}\text { Arno Penzias og Robert Wilson hadde "støy" i en antenne som de ikke fikk bort. Den } \\
\text { kom alle steder fra og tilsvarte en temperatur på } 3.3 \mathrm{~K} \text { ( } 270 \text { kuldegrader). Astronomer } \\
\text { kjente igjen dette som "ekkoet" av Big Bang. }\end{array}$ \\
\hline
\end{tabular}

Framgangen i kunnskap er imidlertid tydelig. Når en ser tilbake på historien, kan en si, jo, det er gode grunner til å akseptere Big Bang kosmologien. Kosmologien framstår som en suksesshistorie om vitenskapelig framgang. Stadig bedre observasjoner har ført til stadig bedre match mellom observasjon og teori. Teorien kan forklare stadig mer.

Ser en nærmere etter i Quantum Generations, er det likevel tydelig at framskrittet ikke går jevnt, men ofte i rykk og napp. Arbeidene til Friedman og Lemaître ble glemt, likeledes forsvant interessen for Big Bang teorien over en tiårsperiode. Når en riktig teori ikke vinner fram, forklares det av Kragh gjennom sosiologiske faktorer, mens de internvitenskapelige faktorene fører framover mot etablert kunnskap (det er slik det faktisk er). Noe av det interessante er at hvis vi går nærmere 
inn på vitenskapshistorien der hvor Kragh vier en bok til temaet, blir det flere farger og nyanser omkring den rasjonelle, røde tråden. Tråden består av flere tråder når en ser etter, noen kommer til og blir borte, noen møtes og andre deler seg.

For eksempel, mye av forarbeidet med å finne hastigheten på galaksene som grunnlag for å konkludere med at de fjerner seg fra oss med en hastighet som er proporsjonal med avstanden ble gjort av en annen astronom tidligere. Og, det var flere typer sammenhenger som kunne passet med dataene enn slutningen Hubble trakk i en tidlig fase, som innebar at hastigheten bort fra oss øker lineært med avstanden. Dessuten: Hubble snakket om "tilsynelatende" hastigheter, han vegret seg for å konkludere med at galaksene beveget seg bort fra oss eller at universet ekspanderte.

Det er riktig å knytte oppdagelsen av det ekspanderende univers til Hubble, men det er mer sammensatt. Kragh (1999) skriver i "Quantum Generations" s. 349 at "It was only in 1930, after Edwin Hubble had established that the galaxies fly apart with a velocity proportional to their distance...." så blir dette mer komplekst når han skriver om det i mer detalj. Kragh (1996) konkluderer i boka "Cosmology \& Controversy":

With the «discovery» of the works of Lemaître and Friedmann in 1930, cosmology experienced a paradigmatic shift. It was only now that Hubble's discovery was transformed to become, i.e., interpreted to be, a discovery of the expanding universe. In a formal hypothetical sense, the expansion of the universe can be traced to Friedmann's work of 1922, and in an observational sense it was supported by Hubble's measurements of 1929. It may even be argued that the expansion had been there all the time since 1917, hidden in Einstein's equations. In any case, it was only with the fusion of theory and observation, as it took place in 1930, that the expanding universe became a reality in the social sense, as a notion widely accepted by the scientific community (Kragh 1996, 32-33).

Vi ser her at samme forfatter (Kragh) har ulik detaljgrad med hensyn til om Hubble's resultater blir knyttet til hans person, eller som i det siste sitatet, blir knyttet til et større forskersamfunn. Det er et forskersamfunn som kommer fram til at det ekspanderende universet er en realitet; dette er Naturen. Vi ser dermed et vesentlig skifte fra framstillingen i lærebøken Tellus til Kraghs framstilling om dette. Naturen er ikke årsak til konsensus slik den var i Tellus, men konsekvensen av konsensus.

Et annet eksempel på at kunnskapsutvikling ikke følger fra direkte observasjon er oppdagelsen av bakgrunnstrålingen i 1965. Oppdagelsen av bakgrunnsstrålingen var en avgjørende støtte for Big Bang teorien. Men astronomer hadde vært på sporet av den allerede i 1948, da de målte energier på et molekyl i verdensrommet, men denne empirien ble ikke satt i sammenheng med teorien.

Framfor alt ser en at erkjennelsen kom gradvis, ved at arbeider som ble glemt, ble tatt fram igjen, og tolket på nye måter. Big Bang kosmologien ble til gjennom at biter $\mathrm{i}$ et puslespill ble satt sammen i en kollektiv anstrengelse av en gruppe astronomer. Framfor alt viser den kollektive dimensjonen seg ved at det spiller ingen rolle hvor riktig en påstand er, hvis ingen tar den opp og fører den videre.

\section{BRUNO LATOURS PERSPEKTIV}

Gjennom Kragh har vi fokusert nærmere på vitenskapshistorien i to trinn; gjennom en framstilling i ett kapittel, dernest gjennom en hel bok viet emnet. I nærbildet begynner vi å komme inn på den levende forskningen, fra dag til dag, konteksten hvor faktaene skrus sammen blir mer framtredende. Det er Bruno Latours anliggende (Latour, 1987), å beskrive naturvitenskap mens faktaene lages, "in action." 
Bruno Latour har et interessant skille mellom Ready-made-science og Science-in-the making; dvs. etablert kunnskap og prosessen med å etablere denne kunnskapen. I Latours framstilling handler naturvitenskap som prosess om å lage "svarte bokser", som er fakta og innretninger som kan flyttes omkring og brukes i ulike situasjoner. En bilmotor er en svart boks når den fungerer, det er bare å vri om nøkkelen og så gjør den det den er laget for. Samtidig krever bilmotoren et apparat omkring seg for å fungere, bensinstasjoner og verksteder for å nevne noe. Dette er del av den svarte boksen.

Naturvitere framstår på ulike måter i Ready-made-science og Science-in-the-making. Mens kunnskapen utvikles og påstander er kontroversielle, er naturvitere "relativister"; naturen er utkommet av kontroversen. Etter at kontroversen er avsluttet, er naturvitere realister, og naturen er grunnen til at kontroversen fikk sin løsning. Det vil si; mens kontroversen pågikk, kunne ikke astronomene si at det er slik og slik fordi naturen er slik, fordi hva naturen er, er nøyaktig det som blir diskutert! Først etterpå kan en si hva som var naturen, og hva som var andre"sosiologiske forklaringer", det vil si grunner til at en feil teori vant fram en tid, eller den riktige ble glemt eller oversett. Latour skiller ikke mellom "natur" og "sosiologiske" forklaringer for å forstå hvordan forskere arbeider. Også hva som er "sosiologiske forklaringer" er tydelig først i etterkant. For Latour er ikke historien egentlig kilde til innsikt i naturvitenskapelige prosesser; han søker å forstå dem mens de skjer, "in action". Latour markerer på den måten enden på veien mot maksimumsversjonen av prosessdimensjonen. Dette er også hovedforskjellen mellom læreboken Tellus og Kraghs bokframstilling som vi har sett. Naturen går fra å være årsak til konsensus til å være resultatet av konsensus.

Latour tar til orde for en metode som ikke forutsetter noe om naturen, eller samfunnet for den del. Den løper omtrent slik (Latour, 1987, p. 15): Start med en læreboksetning, sett den i anførselstegn og lag en snakkeboble av den som peker mot munnen til noen. Til denne snakkende personen tilføyes en annen person som den første snakker til. Plasser dem i en spesifikk situasjon, et sted og en tid, plasser utstyr, maskiner og kolleger omkring dem. Når diskusjonene blir intense, se hvor de ulike personene går og hvilke ressurser de henter for å overbevise kollegene, studer så hvordan de som blir overbevist slutter å diskutere, hvordan personer, situasjoner, steder begynner å bli borte. Til slutt er vi der vi startet, med et sitat uten anførselstegn. Latour viser hvordan fakta blir til ved å gå motsatt vei av det Kragh gjør. Når Latour starter med fakta, er det bare for å nøste tilbake til situasjonen, der det hele startet. Derfra begynner han å granske hvordan forskerne arbeider seg fram til konsensus.

I sin framstilling presenterer Latour en skeptiker som utfordrer kunnskapspåstander, og en talsperson som forklarer, eller leder skeptikeren til å tolke, eller "se" hvordan data fører til konklusjon. Når talspersonen er overbevisende er talspersonen objektiv, hun eller han snakker som representanter for fagfeltet, eller i hvertfall på vegne av laboratoriet. Talspersonen er objektiv når han eller hun ikke kan skilles fra det hun representerer. Hvis beviskjeden (assosiasjonene av ressurser som knyttes til fakta) bryter sammen, blir talspersonen subjektiv og snakker bare på vegne av seg selv.

La oss si at en skeptiker ikke tror på at universet ekspanderer. Han eller hun må da gå inn i de sentrale artiklene og utfordre dem. Men ikke bare de sentrale artiklene, også artiklene som står i referanselista; de allierte som står bak det forfatteren har trukket inn. Skeptikeren må trenge bak teksten og utfordre de sentrale dataene: Viser egentlig Hubbles diagram at hver galakse beveger seg alle bort fra alle andre? Teksten som diagrammet er plassert i er skrudd sammen slik at andre alternativer faller bort; leseren ledes til å se det samme som forfatteren. Men hvis skeptikeren ikke gir seg der heller? Sett at hun ikke stoler på disse dataene? Hun måtte da begi seg inn i instituttene hvor figuren ble laget, og møtt en astronom som viste en PC skjerm med et signal fra teleskopet. Astronomen sier "Ser du?" Men skeptikeren ser ikke annet enn en samling punkter på skjermen; astronomen forklarer at en spektrograf viser galaksens spekter. "Men hvordan vet du det?" spør skeptikeren. Astronomen, som begynner å bli utålmodig, ber en teknikker forklare 
hvordan spektrografen virker. Hva hvis skeptikeren ikke gir seg nå heller? Skal hun bygge sitt eget observatorium? Da vil hun trenge å bygge sterke allianser, mellom forskere, og hun trenger sterke allianser utenfor observatoriet for å bygge et observatorium som kan levere inskripsjoner hun kan bruke. Det er dette som er "teknoscience", for hver aktive forsker i observatoriet (bortsett fra at de i praksis sitter på kontoret og observerer over internett) er det mange flere utenfor observatoriet for å sikre arbeidsro og tilstrekkelig ressurser inne i observatoriet. Målet er at skeptikeren begynner "å se": Når faktumet er etablert, har teksten (for naturviterens praksis) blitt gjennomsiktig; det naturvitenskapelige fenomenet framstår som direkte tilgjengelig.

Ett av de avgjørende instrumentene bak Hubbles diagram er spektrografen. Den sprer lyset fra galaksene som kommer gjennom teleskopet ut til et spektrum hvor en kan se alle regnbuens farger. I dette spektret studerer astronomene linjer som viser tilstanden til stoffer der lyset ble sendt ut. Den som utfordrer Hubbles tolkning vil før eller senere bli ledet til dette instrumentet etter å ha utfordret artiklene. Hele prosessen med å utfordre innebærer å åpne svarte bokser som har vært forsøkt lukket. Selve spektroskopet er en svart boks så lenge alle er enige om at det fungerer og ingen betviler at det gir spektra som kan analyseres og som kan brukes til å argumentere for det ekspanderende univers. Hvis ikke skeptikeren nøyer seg med å utfordre tekstene, må instrumenter og deres inskripsjoner i neste tur utfordres. Eksemplet med Big Bang teorien viser at i laboratoriet (eller observatoriet) ser vi ikke naturen slik den er; vi ser komplisert utstyr og inskripsjoner. Latour definerer instrument som en innretning som lager tegn som brukes i argumentasjon. På veien fra instrumentet oppstår kaskader av inskripsjoner når tegnene fra instrumentet blir omformet gjennom en tolkningsprosess hvor forskerne starter bevegelsen fra snakkeboble til faktum; slik begynner forskerne "å se".

Latour har en forståelse av vitenskapshistorie og natur som framstår som mer egnet som forklaringsmodell når en kontrovers pågår. Vi kan forstå bedre hvordan naturvitenskapen, eller teknoscience, fungerer når det ikke er klart hvem som har vunnet; vi får bedre innsikt i hva det kreves å utfordre kunnskap, hvilke strategier forskerne har for å utfordre hverandre og for å bringe kontroversen til en avslutning i form av konsensus.

\section{Fra prosess til "svart boks" i naturvitenskapens språk}

Det naturvitenskapelige språket har også sine bokser, selv om disse oppleves som gjennomsiktige for en leser som kan knytte sammen deler til helhet på tvers av ulike representasjoner. Det naturvitenskapelige språket er en spesialisering av hverdagsspråket som speiler de spesialiserte hensiktene og funksjonene som naturvitenskapen har i samfunnet. Dette gjør at det fagspråket blir vanskelig tilgjengelig for elever. I Hallidays funksjonelle språksyn (Halliday, 1993) er dette en utvikling hvor prosesser (setninger med verb) blir pakket sammen til "ting", substantiv. For eksempel kan setningen

"Fjerne galakser flytter seg fra hverandre" pakkes sammen til uttrykket "ekspansjon".

Et annet eksempel:

"Alt stoff var samlet i en liten kule med ufattelig høy tetthet og temperatur" kan pakkes sammen til "Det store smellet".

Dette er en språklig ressurs som er viktig fordi

- Det blir mulig å destillere mening fra det konkrete til det abstrakte.

- Prosessene kan inngå i relasjoner mellom begreper og gis ulike kvaliteter, i eksempelet overfor så kan nominaliseringen "temperatur" gis kvaliteten "ufattelig høy". Slike kjeder av modifikatorer kan bli ganske lange i naturvitenskapelige tekster!

Davis Baird (2004) har et perspektiv på vitenskapelige instrumenter som står nær Latour. Han vektlegger at instrumenter rommer, eller bærer kunnskap ved at de kan framvise et fenomen på 
en pålitelig måte, selv om instrumentets funksjon ikke er forstått eller er omdiskutert. Teknologien er i dette bildet et selvstendig kunnskapsdomene (også poengtert av andre forskere på teknologiens historie, som Staudenmaier (1985)). Kunnskapsutvikling skjer både gjennom å bygge bokser i språket, og i form av teknologi.

De kunnskapsbyggende prosessene i naturvitenskapen innebærer dermed å bygge bokser som både språklige og tekniske verktøy. De møtes i instrumentet, i dette tilfellet spektrografen, som kan bidra til teoribygging (språklige bokser) gjennom argumentasjon når den selv fungerer som svart boks.

\section{ULIKE NIVÅER PÅ NATURVITENSKAPEN SOM PROSESS I UNDERVISNINGEN}

Utviklingstrekkene i de ulike framstillingene diskutert over kan oppsummeres slik: I læreboken Tellus er universets ekspansjon tilgjengelig for direkte observasjon, og Big Bang følger logisk av det. Dette er ikke en kritikk av framstillingen all den tid teksten ikke forsøker å synliggjøre naturvitenskap som prosess. I læreboken Trigger, som er knyttet til LK06 læreplanen, pekes det på et tidsspenn fra ideen om Big Bang til det kom empirisk støtte som overbeviste mange astronomer. I Kraghs kapittelframstilling kommer et antall sentrale personer til syne, og utviklingen følger ikke en rett linje. I Kraghs bokframstilling av Big Bang teorien blir forskersamfunnet som argumentasjonsfellesskap tydelig, og et vendepunkt kommer når naturen går fra å være årsak til konsensus til å bli resultatet av konsensus. Å forstå naturvitenskapelige prosesser uten fasit i hand (naturen er resultatet av konsensus) har vært Latours anliggende.

Denne artikkelen er en utforskning av hvordan fokus på naturvitenskapen som prosess kan arte seg og hvilke ansatser som kan brukes. Det er imidlertid ikke hensikten her å foreslå konkrete undervisningsopplegg. Noe vil likevel sies.

Det synes klart at lærer og elever er avhengig av ulike kilder for å bruke vitenskapshistorie i undervisningen. Et didaktisk valg er da hvor vekten skal ligge mellom læreren som formidler og som tilrettelegger og veileder i forhold til elevenes egen utforskning av et emne. En mulighet er at læreren setter elevene på sporet av stoff om enkeltforskere som det arbeides med i grupper, og så settes bildet sammen i plenum. Nedenfor pekes på noen grep som kan fungere dramaturgisk for å gå dypere i prosessdimensjonen i et tema.

Et utgangspunkt for å trekke inn prosessdimensjonen er å gjøre elevene oppmerksomme på at det er en prosess som ligger bak etablering av fakta. Et første steg kan dermed være å sammenligne framstillingen i to læreboktekster som vist i figur 1 og figur 2. Læreren kan peke på uttrykk som fungerer som svarte bokser. Disse kan dernest brukes til å pirke i framstillingen i form av kritiske spørsmål til tekstene:

Hva menes med at astronomene "ser"? (Hvordan det tok astronomene tid å sette sammen dataene til å bli et bilde av et univers i ekspansjon, og deretter å utvikle en modell for "Det store smellet”)

Var det alle astronomer som "så?" (Læreren kan finne litteratur på Steady State teorien) Hvordan kommer forskerne fram til et faktum, hvordan begynner forskere å "se"? (Forskere , tolker, spekulerer, bruker metaforer, forklarer, presenterer, omformer osv. i et forskerfellesskap. De ser ikke fakta direkte). 


\section{KONLUSJON OG IMPLIKASJONER}

Det er flere nivåer eller styrkegrader i å åpne for prosessiden bak et faktum, avhengig av hvor mye en fokuserer på steder, personer eller tidsintervaller. Ulike foki kan beskrives som:

1. Vise at en teori har utviklet seg over en periode på flere tiår med noen av de sentrale navnene: Einstein, Lemaître, Friedman, Hubble, Gamow; at mange forskere som forskerfellesskap stod bak.

2. Vise hvordan teorien har utviklet seg over tid: Ikke en rett fram bevegelse, resultater blir glemt og tatt fram igjen, konkurrenter kommer og går, flere brikker faller på plass. Det er ikke direkte sammenheng mellom motstridende data og endringer i teoriverket, utviklingen kan skje i sprang (Kuhn, 1996).

3. Vise hvordan forskere jobber mens kontroversen pågår; hvordan de bygger fakta "svarte bokser"; språklig og instrumentelt.

Hvis det faglige fokuset er det sentrale, vil det være 1 og 2 som kanskje blir viktig. I et allmenndannende perspektiv, hvor det handler om å forstå "teknoscience" blir 3 viktigere. Det viktigste dilemmaet er hva som skal være førende; prosessen eller den ferdig etablerte kunnskapen. Når måten forskerne arbeider på fokuseres uten at en vet hva som blir utfallet, må den etablerte kunnskapen komme i bakgrunnen, hvis den blir tydelig går vi fra 3. til 2. eller 1. i punktene over.

Latours fokus på "science-in-action" åpner muligheter for at noen av normene og rollene i utforskende arbeidsmåter kan gjenskapes i klasserommet. Vi så ovenfor at et helt sentralt aspekt når talspersonen skulle overbevise skeptikeren, var at skeptikeren måtte "se" det samme som talspersonen: Lysstriper måtte ses som spektra fra galakser, og striper i disse igjen måtte ses som uttrykk for universets ekspansjon. Å "se" dette gir seg ikke selv; data taler ikke for seg. Det samme foregår i naturvitenskapelige artikler da med tekstlige representasjoner: Leseren ledes gjennom teksten til å komme til samme konklusjon som forfatterne; andre måter å tolke tegnene i teksten på blir argumentert mot. Som en del av sosialisering inn en spesialisert faglig diskurs, lærer elevene å se verden på nye måter gjennom begrepsdanning og en ny måte å bruke språk på. Å lære å se skjer samtidig med at de lærer naturfagets spesialiserte språk (Jewitt, 2006). En mulighet er å gi rollen som "talsperson" og "skeptiker" til elever når de skal dele og drøfte empiriske resultater med hverandre.

I naturfag lærer elevene implisitte syn på hvordan kunnskap blir til. Når forskningsprosser blir sterkt komprimert i lærebokas framstilling kan de formidle en type "direkte rapportering" som også synes å være typisk for elevenes eksperimentelle arbeid, med lite rom for refleksjon. (af Geijerstam, 2006; Tiberghien, Veillard, Le Maréchal, Buty, \& Millar, 2001). Knain (2001) fant et bilde av naturvitenskapelige prosesser som individsentrerte i lærebøker. Det er individer som gjør oppdagelser gjennom eksperimentelt arbeid. Behovet for å tolke og argumentere over empiriske data underkommuniseres. Slike framstilinger er ikke egentlig uriktige. Men de er framstilt for et bestemt formål; når en prosess som strekker seg over flere tiår skal presenteres over kanskje en halv side og det skal være klart hvordan akkurat dette faktumet ble oppdaget, må noe framheves og noe velges bort. Det er da lett å miste at data kan være omstridte, uklare og kan tolkes på flere måter "in action". Dette er et perspektiv som er viktig for å skjønne kontroverser elevene møter i verden utenfor skolen, og er dermed viktig for elevenes allmenndannelse (Kolstø, 2008).

Denne artikkelen har pekt på hvordan veien videre fra en mimimumsvariant av naturvitenskapens prosessdimensjon kan utvides i forhold til ett bestemt case. Hensikten har ikke vært å peke på generelle trekk ved naturvitenskapelige metoder, det er omdiskutert i fagdidaktisk litteratur i hvilken grad en kan snakke om en generell naturvitenskapelig metode. I alle tilfeller kan den viktigste verdien i elevenes utbytte ligge i å gå inn i konkrete faglige utviklingsforløp slik at den idemessige utviklingen, den enkelte forskerens bidrag og betydning av kontroverser og argumentasjon i et forskersamfunn kan tre fram. 


\section{SLUTTNOTE}

Denne studien er del av prosjektet "Elever som forskere i naturfag" (ElevForsk) finansiert av Norges forskningsråd gjennom programmet Praksisrettet FoU for barnehage, grunnopplæring og lærerutdanning (PraksisFoU).

\section{LITTERATUR}

af Geijerstam, Å. (2006). Att skriva i naturorienteande ämnen i skolan. Uppsala: Acta Universitas Upsaliensis. Studia Linguistica Upsaliensia, 3.

Baird, D. (2004). Thing knowledge. A Philosophy of Scientific Instruments. Berkeley and Los Angeles: University of California Press.

Driver, R., Newton, P., \& Osborne, J. (2000). Establishing the Norms of Scientific Argumentation in Classrooms. Science Education, 84, 287-312.

Ekeland, P. R., Johansen, O.-I., Rygh, O., \& Strand, S. B. (1997). Tellus 8. Natur- og miljøfag for ungdomstrinnet. Oslo: Aschehoug.

Finstad, H. S., Kolderup, J., \& Jørgensen, E. C. (2006). Trigger 8. Oslo: Damm.

Halliday, M. A. K. (1993). On the Language of Physical Science. In M. A. K. Halliday \& J. R. Martin (Eds.), Writing science. Literacy and Discursive Power (pp. 54-68). London \& Washington D. C.: The Falmer Press.

Hodson, D. (1996). Laboratory work as scientific method: three decades of confusion and distortion. Journal of Curriculum Studies, 28(2), 115-135.

Jewitt, C. (2006). Technology, Literacy, Learning. A multimodal Approach. London \& New York: Routledge.

Knain, E. (2001). Ideologies in school science textbooks. International Journal of Science Education, 23(3), 319-329.

Kolstø, S. D. (2008). Science education for democratic citizenship through the use of the history of science. Science \& Education, 17, 977-997.

Kragh, H. (1996). Cosmology and Controversy. The Historical Development of Two Theories of the Universe. Princeton: Princeton University Press.

Kragh, H. (1999). Quantum Generations. A History of Physics in the Twentieth Century. Princeton: Princeton University Press.

Kuhn, T. S. (1996). The Sctructure of Scientific Revolutions. Chicago: The University of Chicago Press.

Latour, B. (1987). Science in Action. Cambride: Harvard University Press.

Matthews (1994). Science Teaching: The Role of History and Philosophy of Science. New York and London: Routledge.

Staudenmaier, J. M. (1985). Technology's Storyteller. London \& Cambridge: The Society for the History if Technology \& The MIT Press.

Tiberghien, A., Veillard, L., Le Maréchal, J.-F., Buty, C., \& Millar, R. (2001). An Analysis of Labwork Tasks Used in Science Teaching at Upper Secondary School and University Levels in Several European Countries. Science Education, 85, 483-508.

Utdanningsdirektoratet (2006). Loreplanverket for Kunnskapsløftet. Oslo. 